\title{
EVOLUÇÃO DO USO DO SOLO E DA COBERTURA VEGETAL NA REGIÃO DA SERRA DO BOTURUNA, ESTADO DE SÃO PAULO

\author{
Sandro Francisco Detoni ${ }^{1}$
}

\begin{abstract}
Resumo: Esta pesquisa analisou a evolução do uso do solo e da cobertura vegetal na região da Serra do Boturuna, Estado de São Paulo. Essa região possui uma estrutura paisagística peculiar, o que contribuiu para o seu tombamento pelo Conselho de Defesa do Patrimônio Histórico, Arqueológico, Artístico e Turístico do Estado de São Paulo (Condephaat). A análise baseou-se nos mapeamentos de uso e ocupação do solo referente aos anos de 1986 e de 2002 efetuados pela Empresa Paulista de Planejamento Metropolitano (Emplasa). A utilização de um Sistema de Informação Geográfica (SIG) possibilitou a geração de mapas e de dados quantitativos sobre a evolução do uso do solo e da cobertura vegetal na região. As áreas de cobertura vegetal obtiveram as maiores modificações no período, assim, destaca-se 0 aumento da cobertura florestal e a diminuição das áreas compostas por capoeiras e por campos. Dessa forma, por meio desses dados é possivel sugerir que o tombamento da serra, possivelmente, contribuiu para a preservação e 0 aumento da cobertura florestal na região.
\end{abstract}

Palavras-Chave: Serra do Boturuna; Área Natural Tombada; Uso e Ocupação do Solo; Geoprocessamento.

\section{Introdução}

A Serra do Boturuna, ou Voturuna, localiza-se entre os municípios de Santana de Paranaíba e Pirapora do Bom Jesus, no Estado de São Paulo. Esses municípios integram e estão a noroeste da Região Metropolitana de São Paulo (RMSP), conforme a Figura 1.

Apesar do amplo desmatamento, a região possui alguns fragmentos de cobertura florestal preservada ou em distintos estágios de recomposição. Esses remanescentes florestais, juntamente com a estrutura paisagística da região, contribuíram para o tombamento da serra pelo Conselho de Defesa do Patrimônio Histórico, Arqueológico, Artístico e Turístico do Estado de São Paulo (Condephaat).

Fatores como o clima, a vegetação, os solos, a litologia e, sobretudo, a estrutura topográfica conferem à região uma diversidade paisagística peculiar. Além desses condicionantes naturais, a interferência antrópica, por meio das minerações e de outras formas de uso e ocupação do solo, determinou e ainda determina alterações significativas na paisagem local. Assim, a escolha da região da Serra do Boturuna para a realização deste trabalho deve-se não somente às características peculiares, que contribuíram para o seu tombamento junto ao Condephaat, mas também as formas de uso e ocupação do solo presentes na região.

A delimitação da área de estudo baseou-se no entorno da Área Natural Tombada (ANT) da Serra do Boturuna. Para isso, consideraram-se a hidrografia e o sistema viário, obtidos nas cartas na escala 1: 10.000 do Sistema Cartográfico Metropolitano (SCM). Seus limites foram compostos pelos seguintes atributos: rio Tietê, reservatório do Rasgão, Estrada dos Romeiros (SP-312), limites entre Pirapora do Bom Jesus e Araçariguama e Santana de Parnaíba e Araçariguama, representados por um curso d'água. 0 limite sul foi estabelecido por meio de uma estrada e do ribeirão

\section{Objetivos}

Um dos principais pressupostos do tombamento da Serra do Boturuna decorreu da preservação dos remanescentes de vegetação da região, assim, para verificar a eficácia ou influência desse instrumento jurídico, essa pesquisa analisou a evolução do uso e ocupação do solo ${ }^{2}$ e da cobertura vegetal na região com base nos mapeamentos temáticos dos anos de1986 e de 2002.

${ }^{1}$ Geógrafo e Mestrando do Programa de Pós-Graduação em Geografia Física da Faculdade de Filosofia, Letras e Ciências Humanas da Universidade de São Paulo (detoni@usp.br)

${ }^{2}$ Alguns autores utilizam o termo "terra". Porém, utilizou-se o termo solo seguindo a terminologia adotada pela EMPLASA em seus mapeamentos. 


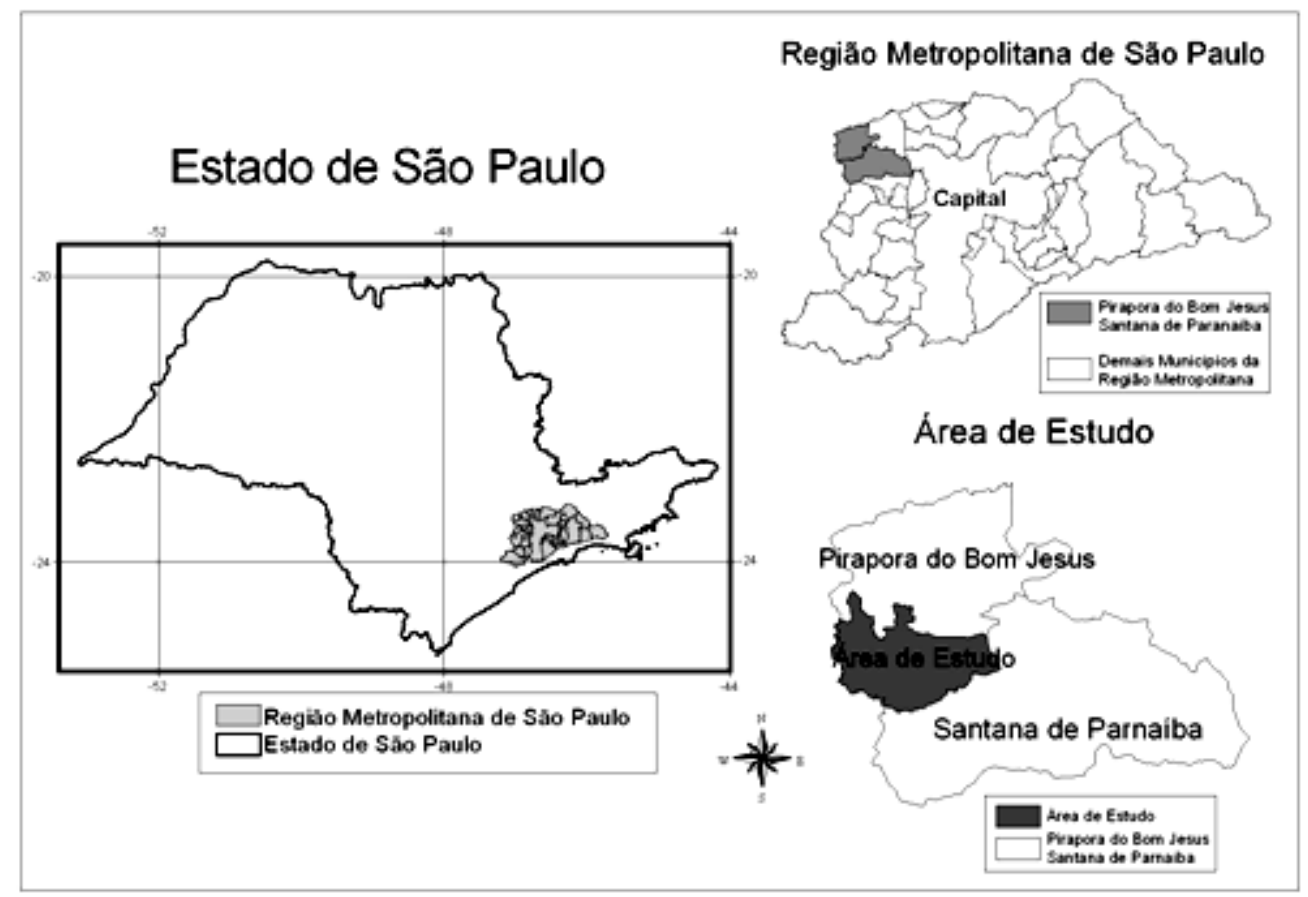

Figura 1 Mapa de localização da área de estudo (sem escala)

\section{Características da cobertura vegetal}

A distribuição da cobertura vegetal na região da Serra do Boturuna condiciona-se aos seguintes fatores: climáticos, geomorfológicos, pedológicos, litológicos e influência antrópica. De acordo com as classificação proposta por AB'SÁBER (2003), a região localiza-se no Domínio Morfoclimático dos Mares de Morros. $O$ autor utiliza o termo morfoclimático para destacar o caráter sistêmico da paisagem. Entretanto, em cada domínio morfoclimático, há um sistema de inter-relação entre os componentes morfológicos, pedológicos, climáticos e vegetacionais. Esses fatores compõem, assim, uma determinada fisionomia de paisagem.

No Domínio Morfoclimático dos Mares de Morros, o relevo, que é caracterizado pelo planalto, juntamente com a atuação de sistemas atmosféricos, determinam o tipo climático da região. De forma geral, o relevo e o clima também condicionam a distribuição da vegetação neste domínio, que se constitui num contexto mais amplo pela cobertura florestal de Mata Atlântica. Todavia, há distintos fatores de ordem local que podem influenciar sobre a distribuição desse tipo florestal.

Com relação à abrangência geomorfológica, o domínio morfoclimático em questão se insere na unidade de relevo do Planalto Atlântico. Logo, verifica-se que a distribuição da vegetação nesse planalto relaciona-se, em certo grau, com a compartimentação do relevo. De acordo com o Mapa de Vegetação do Brasil (IBGE, 2004), no Planalto Atlântico, há o predomínio da Floresta Ombrófila Densa. $O$ termo ombrófila caracteriza a ausência de um período biológico seco ou, quando ocorrer, envolve dois meses. 0 critério para a elaboração desse mapa considerou a distribuição fitoecológica pautada na disponibilidade de água, na tipologia dos solos e no clima. Entretanto, supõe-se que em algumas áreas do Planalto Atlântico, a vegetação original fosse formada por campos naturais como nos terrenos Cenozóicos da Bacia Sedimentar de São Paulo. Essa característica peculiar está relacionada, em especial, aos solos da região.

Além da floresta ombrófila densa e dos campos naturais, também é possível identificar alguns enclaves de cerrado e até mini-enclaves de cactáceas, relacionados à hipótese da influência de fatores paleoclimáticos e paleogeográficos.

Com o detalhamento da escala de análise, destacam-se distintas formações vegetacionais que possuem influência de fatores climáticos ou das condições pedológicas locais. Nesse sentido, ao considerar o critério da sazonalidade e com base nos 
critérios de classificação climática do IBGE (2004), sugere-se que a formação vegetal predominante na região da Serra do Boturuna compõe-se, principalmente, da Floresta Estacional Semidecidual que se relaciona ao predomínio na região de duas tipologias climáticas: uma fria e seca e outra quente e úmida. A característica estacional decorre do déficit hídrico da estação fria e seca, logo, nesse período ocorre queda das folhas em algumas espécies.

É possível afirmar que os solos, o clima e a altitude são importantes condicionantes na distribuição da vegetação na Serra do Boturuna. O tipo florestal da região é composto por espécies decíduas e semidecíduas. 0 gradiente topográfico região ainda permite inserir a área de estudo no grupo de formações vegetais Montana ${ }^{3}$. Porém, não há homogeneidade nesse tipo florestal, pois a distribuição da vegetação condiciona-se, sobretudo, às características pedológicas.

A altitude e as características dos solos fazem com que determinadas áreas da Serra do Boturuna possuam como característica fisionômica da vegetação um campo de altitude ou algo muito próximo a um campo cerrado.

\section{Materiais e Métodos}

\section{Base de Dados}

A base de dados para analisar a evolução do uso do solo e da cobertura vegetal foram os mapeamentos dessa temática realizados pela Empresa Paulista de Planejamento Metropolitano S. A. (Emplasa) referente aos anos de 1986 e de 2002.

Optou-se por utilizar tais dados pela fácil disponibilidade dos produtos cartográficos temáticos, assim, não foi necessário efetuar os procedimentos de fotointerpretação para a geração de uma base cartográfica sobre o uso do solo e cobertura vegetal. Com base nos mapeamentos temáticos disponíveis e com o apoio instrumental de um Sistema de Informação Geográfica (SIG) geraram-se dois mapas temáticos e um conjunto de dados que demonstraram de forma qualitativa e quantitativa as modificações na distribuição das categorias de uso do solo e cobertura vegetal na área de estudo.

\section{Uso e ocupação do solo da Região Metropolitana de São Paulo em 1986}

O levantamento do uso e ocupação do solo da RMSP referente ao período 1986 baseou-se na fotointerpretação de imagens aéreas na escala 1: 10.000, em recobrimento aerofotogramétrico realizado em 1986/89 pela Terra Foto Aerolevantamentos. 0 apoio conceitual das classes de uso e ocupação do solo advém de diversas fontes. Porém, o apoio principal foi o Levantamento da Cobertura Vegetal Natural e do Reflorestamento no Estado de São Paulo, trabalho realizado pela Secretaria da Agricultura do Estado de São Paulo (SÃO PAULO, 1975), e os trabalhos realizados pela pesquisadora Dora de A. Romariz', em 1974.

O Quadro 1 descreve as categorias de uso e ocupação do solo presentes na região da Serra do Boturuna. Posteriormente, efetuou-se a análise conceitual das categorias relacionadas à cobertura vegetal.

Quadro 1 Classes de uso e ocupação do solo do mapeamento de 1986

\begin{tabular}{|c|}
\hline Categorias de Uso e Ocupação do Solo \\
\hline Mata \\
\hline Capoeira \\
\hline Campo \\
\hline Campo Sujo \\
\hline Vegetação de Várzea-Campo \\
\hline Vegetaçẫo de Várzea-Capoeira \\
\hline Vegetaçẫo de Várzea-Mata \\
\hline Reflorestamento \\
\hline Horticultura \\
\hline Cultura \\
\hline Granja \\
\hline Solo Exposto \\
\hline Chácara \\
\hline Olaria \\
\hline Área Urbanizada \\
\hline Loteamento Desocupado \\
\hline Mineraçẫo em Atividade \\
\hline Mineraçẫo Abandonada \\
\hline Indústria \\
\hline Movimento de Solo \\
\hline Equipamento Urbano \\
\hline Outro Uso \\
\hline
\end{tabular}

Fonte: EMPLASA (1986)

Mata

Segundo a classificação da UNESCO (1973), refere-se ao tipo de vegetação constituído por árvores de porte superior a cinco metros cujas copas se toquem (no tipo mais denso) ou que propiciem uma cobertura de, pelo menos, $40 \%$ (nos tipos mais abertos). No entanto, esse conceito é muito amplo e envolve os diversos tipos de matas, sendo necessário um maior detalhamento.

${ }^{3} \mathrm{O}$ grupo de formação vegetacional Montana, entre as latitudes $16^{\circ}$ e $24^{\circ}$, caracteriza-se por altitudes entre 500 e $1500 \mathrm{~m}$.

${ }^{4}$ Informações adquiridas por meio de pesquisas realizadas nos arquivos da Emplasa. Destaca-se o seguinte trabalho: Reconhecimento de Alguns Padrões de Vegetação nas Áreas das Bacias Hidrográficas Referentes às Represas Billings e Guarapiranga. 
No Levantamento da Cobertura Vegetal Natural e do Reflorestamento no Estado de São Paulo (SÃO PAULO, 1975), o conceito de mata refere-se à formação vegetal inteiramente dominada por árvores de estrutura complexa, que apresenta grande riqueza de espécies e que possui três estratos distintos:

- Estrato superior: relativamente pouco denso é formado por indivíduos de 15 a $20 \mathrm{~m}$ de altura de troncos cilíndricos e com esgalhamento médio a alto;

- Estrato intermediário: com alta densidade é constituído por indivíduos de 10 a $15 \mathrm{~m}$ com copas mais fechadas;

- Estrato inferior: constituído por ervas e arbusto de até três metros de altura.

Romariz definiu quatro padrões de matas: tipos 1, 2, 8 e C. 0 padrão de mata proposto para o mapeamento de 1986 enquadra-se no tipo 1 e 2. No padrão do tipo 1, as copas das árvores formam um dossel bastante fechado, o que propicia uma cobertura superior a $80 \%$. Esse tipo de mata, também apresenta um estrato arbóreo mais baixo e, por vezes, até um arbustivo, isso faz com que a cobertura vegetal torne-se mais densa. Nas matas do tipo 2, as copas das árvores mais altas não formam um dossel tão fechado quanto nas do tipo 1, o que permite a passagem de maior quantidade de luz. No geral, a cobertura florestal varia entre $50-60 \%$ e 80\%. As árvores são superiores a $10 \mathrm{~m}$, mas seus troncos, em média, possuem um diâmetro entre 20 e $40 \mathrm{~cm}$. A maior incidência de luz faz com que ocorra o desenvolvimento de estratos arbustivos e subarbustivos.

\section{Capoeira}

De acordo com AB'SÁBER (1978), as capoeiras e os capoeirões são termos utilizados na linguagem rural Paulista, sendo uma herança de termos do tronco indígena tupi. Esses termos significam matas em recomposição e possuem relação com o longo período de pousio em solos agrícolas. A capoeira, segundo o Levantamento da Cobertura Vegetal Natural e do Reflorestamento no Estado de São Paulo, é definida como uma vegetação secundária que sucede à derrubada da floresta. Essa vegetação é constituída, em especial, por indivíduos lenhosos de segundo crescimento. Sua composição florestal apresenta, em sua maioria, espécies da floresta anterior e espécies espontâneas, que invadem as áreas devastadas. Assim, os estratos da capoeira variam do porte arbustivo até 0 arbóreo com árvores finas e compactamente dispostas.

Ao seguir os critérios de classificação propostos por Romariz, as capoeiras enquadram-se nas matas do tipo 8. Esse tipo de mata possui uma ampla variação fisionômica. No geral, as árvores de maior porte ocorrem em número menor e o distanciamento das copas é maior o que forma uma cobertura florestal entre $40 \%$ e $50 \%$. As árvores possuem, normalmente, diâmetro inferior a $30 \mathrm{~cm}$, casca lisa, muito ramificada e com altura que pode atingir de oito a $10 \mathrm{~m}$. A maior incidência de luz no estrato arbustivo resulta em seu maior desenvolvimento, diferente do que acontece nas matas do tipo 2 . Quando apresentarem um estrato arbóreo bem desenvolvido, as matas do tipo 8 podem ser denominadas como capoeirão, sendo um estágio muito próximo de uma floresta primária.

\section{Campo Sujo}

$\mathrm{Na}$ classificação proposta por Romariz, definiu-se essa vegetação como do tipo $C$, caracterizado pela predominância de arbustos e subarbustos, sem a presença de árvores altas, apenas algumas muito baixas que variam no máximo de seis a sete metros. 0 diâmetro médio das espécies é de $10 \mathrm{~cm}$, com troncos lisos e claros. No geral, a altura média dessa classe de cobertura vegetal varia entre cinco e seis metros. Considerada uma transição entre campo e capoeira, o aspecto fisionômico dessa categoria aproximase mais da categoria capoeira do que campo.

\section{Campo}

Esse tipo de vegetação possui como característica uma cobertura vegetal graminóide e herbácea, sem a presença de árvores. Assim, a categoria campo possui apenas o estrato herbáceo.

\section{Reflorestamento}

Segundo o Levantamento da Cobertura Vegetal Natural e do Reflorestamento no Estado de São Paulo, os reflorestamentos são formações disciplinadas e homogêneas quanto às essências, plantadas em maciços para suprimento industrial e em talhões isolados, geralmente para consumo interno dos estabelecimentos rurais. Normalmente, os reflorestamentos apresentam limites regulares e carreadores (caminhos) definidos.

\section{Uso e ocupação do solo da Região Metropolitana de São Paulo e Bacia do Alto Tietê em 2002}

Com aporte financeiro do Fundo Estadual de Recursos Hídricos (FEHIDRO), o mapeamento do uso e ocupação do solo da RMSP e Bacia do Alto Tietê, encomendado pela Emplasa e realizado pela Empresa de Aerofotogrametria ENGEFOTO, baseou-se na interpretação em tela de imagens do satélite de alta resolução Ikonos, tomadas no ano de 2002. Essas imagens possuíam resolução espacial de $0,82 \mathrm{~m}$ no nadir, porém, foram re-amostradas para uma resolução espacial de um metro. 
Assim como no mapeamento de 1986, na interpretação das imagens Ikonos, a menor unidade representada cartograficamente foi um hectare, ou seja, uma quadrícula com lados de quatro milímetros. Nessa escala de trabalho, a representação das edificações com áreas menores que um hectare ocorreu por meio de simbologia específica. Logo, incorporaram-se à vegetação predominante de entorno, os fragmentos de vegetação menores que a unidade mínima estabelecida.

De forma geral, utilizou-se a mesma base conceitual das categorias de uso e ocupação do solo do mapeamento de 1986. No entanto, com o intuito de diminuir a legenda, suprimiram-se algumas categorias. As categorias matas e campo sofreram algumas generalizações, com isso, os conceitos dessas tipologias vegetais foram mais abrangentes.

A caracterização das matas ocorreu com base no conceito da UNESCO (1973) que considera como chave de interpretação as árvores com porte superior a cinco metros ou menos de cinco metros em formações que propiciem uma cobertura de $40 \%$. Ao seguir esse pressuposto, as coberturas florestais menores que $40 \%$ e entre 40 e $50 \%$, que possuem árvores de menor porte, incluem-se na categoria capoeira. Com isso, atribui-se a essa categoria o porte arbustivo alto e o porte florestal baixo. Uma importante modificação com relação ao mapeamento de 1986, consistiu-se na inclusão da categoria campo sujo como capoeira. Efetuou-se a delimitação da vegetação de várzea com base no padrão fisionômico da imagem, ou seja, considerou-se somente a vegetação ripária identificadas nas imagens. Assim, não se delimitou as áreas de várzeas que possuíssem cobertura compostas por matas e por capoeiras. As categorias que representavam as culturas de ciclo longo, horticulturas e granjas passaram a compor a categoria de hortifrutigranjeiro, incluiu-se também, nessa categoria, a psicultura. Alocaram-se os movimentos de terra e os solos expostos numa só categoria. Com relação à atividade minerária, diferente do mapeamento de 1986 que apresentou duas tipologias de mineração (em atividade e as abandonadas), esse mapeamento utilizou somente a categoria mineração. Ao considerar essas modificações, o mapeamento do uso e ocupação do solo da RMSP e Bacia do Alto Tietê 2002 apresentou as seguintes categorias:

Mata

Baseou-se no conceito da UNESCO (1973) que considera as áreas que possuem cobertura florestal maior que $40 \%$. Assim, nesta categoria, incluem-se os capoeirões.

\section{Capoeira}

Considerou-se uma transição entre campo e mata. A capoeira possui cobertura florestal, portanto, as árvores apresentam menor porte.

\section{Campo}

O campo possui gramíneas com altura que varia entre 10 e 15 $\mathrm{cm}$, subarbustos, e, raramente, arbustos distanciados um do outro. A cobertura pode ser contínua ou com trechos de solo descoberto. Inclui-se também, nesta categoria, o campo sujo.

\section{Reflorestamento}

Caracterizados por formações arbóreas e homogêneas, cultivadas com fim econômico. Por exemplo, espécies do gênero eucalyptus ou do gênero pinus.

\section{Hortifrutigranjeiro}

Correspondem às culturas de ciclo longo: árvores ou arbusto de espécies frutiferas, arroz, trigo, milho, entre outros; horticulturas representadas por hortaliças e flores; e, granjas caracterizadas por suas instalações de avicultura e produção de ovos.

Movimento de terra/solo exposto

Identificadas pelas seguintes características: áreas de soloplanagem; solo exposto preparado para o plantio; áreas com ausência de cobertura vegetal; e áreas de atuação de processos erosivos.

\section{Mineração}

Delimitaram-se as minerações conforme do aspecto fisionômico da imagem, por isso, não houve a distinção de minerações ativas e abandonadas. 0 mapeamento considerou as áreas de extração mineral e entorno o que incluiu as instalações e as áreas com cobertura vegetal suprimida.

\section{Área Urbanizada}

Constituem-se de áreas com arruamento, ocupadas da seguinte forma: residencial, comercial ou serviços.

\section{Chácara}

Correspondem aos loteamentos de chácaras destinadas à recreação ou ao uso residencial, identificados por meio de suas sedes, dos pomares, das hortas, do solo preparado para o plantio, dos lagos, dos bosques, das quadras, das piscinas, entre outros. (pomares e hortas enquadram-se nesta categoria quando possuem a função de subsistência).

\section{Loteamento desocupado}

Caracterizaram-se os loteamentos desocupados por meio do conjunto de arruamento geométrico ou irregular com $10 \%$ de ocupação por edificações com ou sem cobertura vegetal. Assim, essa categoria de uso do solo pode se localizar em áreas urbanizadas ou em áreas isoladas.

\section{Favela}

Considerou-se essa categoria como um conjunto de unidades habitacionais (madeira ou alvenaria) que apresenta aspecto 
fisionômico denso e desordenado.

Indústria

A identificação baseou-se nas grandes edificações com pátio de estacionamento, localizadas dentro ou fora de áreas urbanizadas. Incluíram-se também as olarias nessa categoria de uso e ocupação do solo.

\section{Equipamento urbano}

Constituíram-se de estabelecimento, espaços ou instalações destinados ao ensino, à saúde, ao lazer, à cultura, à assistência social, ao culto religioso ou à administração pública. Num contexto geral, tais estabelecimentos possuem ligação direta, funcional ou espacial com usos residenciais. Também fizeram parte dessa categoria de uso e ocupação do solo os estabelecimento ou instalações sujeitos à preservação ou ao controle específico, por exemplo, os monumentos históricos, as instalações dos mananciais de abastecimento de água, as áreas de valor estratégico para a segurança pública e as áreas de valor paisagístico especial. Delimitaram-se as matas e as capoeiras dispostas dentro dessa categoria com área superior a um hectare.

\section{Aterro Sanitário/Lixão}

0 aterro sanitário caracteriza-se pela deposição de resíduos sólidos em áreas que possuem determinado controle relacionado à impermeabilização do solo, ao estabelecimento de uma estação de tratamento de chorume ao sistema de drenagem dos efluentes e do biogás. Nesse sentido, o lixão não possui tal controle sanitário. Lagoa

Determinadas com base nos corpos d'água superiores a 10 ha que resultam do represamento de córrego ou ribeirões.

Outro uso

Definiram-se como outro uso, as tipologias de uso e ocupação do solo que não se inserem nos conceitos descritos, tais como, os comércios e serviços ao longo das estradas, os movimentos de solo na fase de construção, os postos de gasolina, entre outros.

\section{Procedimentos Técnicos e Metodológicos}

A geração e a combinação dos mapas temáticos ocorreram com o auxílio do SIG ArcView 3.3 e da extensão Spatial Analyst 2.0. Entre outras características, uma das principais atributos de um SIG é a fácil e precisa integração dos dados geo-referenciados, sendo de fundamental importância para o propósito da pesquisa.

A utilização do SIG foi precedida pela geração de dados por intermédio dos documentos de base e aquisição direta desses dados em formato vetorial.
As cartas de uso e ocupação do solo de 1986 foram convertidas do formato analógico para o digital por meio da utilização de um scanner, o que gerou imagens de um bit com resolução espacial de $72 \mathrm{DPI}$ (Dot Per Inches), ou seja, cada pixel nas imagens possuiu $0,3527 \mathrm{~mm}$. Essas bases digitais foram geo-referenciadas ${ }^{5}$ e vetorizadas no software AutoCad Map 2000. Cabe mencionar que o processo de conversão das cartas do formato analógico para o digital gerou distorções, porém, software utilizado não fez 0 ajustamento da imagem, o que inferiu maior quantidade de erros à base e, conseqüentemente, diminuiu sua precisão.

Foram vetorizados os polígonos que representaram as distintas categorias de uso e ocupação do solo da área de estudo. Mediante as ferramentas de análise espacial do AutoCad Map 2000, foram geradas as topologias e as tabelas de atributos dos polígonos. Posteriormente, a base cartográfica em formato vetorial, editada e geo-codificada, foi exportada em formato shape (ArcView) para a elaboração dos mapas temáticos propostos.

As cartas de uso e ocupação do solo da que abrangem a região da Serra do Boturuna foram adquiridas em formato vetorial junto à Emplasa, por isso, não se fez necessário o processo de vetorização. As informações foram editadas no AutoCad Map 2000 e exportadas em formato shape, para a elaboração dos mapas no ArcView.

Os mapas que descrevem as evoluções do uso do solo e da cobertura vegetal da área de estudo foram elaborados com técnicas de geoprocessamento presentes nas extensões do ArcView 3.3. Para isso, efetuou-se a combinação dos mapas de uso e ocupação do solo de 1986 e de 2002, convertidos numa estrutura raster com resolução espacial dos pixels de 2,81 m, sendo a resolução mínima permitida pelo software para as bases digitais.

A interpolação dos dados ocorreu mediante a metodologia pixel a pixel, ou seja, os pixels dos dois mapas foram sobrepostos e aplicou-se uma operação aritmética para gerar um terceiro pixel que resultou no mapa de evolução das categorias temáticas em questão.

Para cada categoria temática nos dois períodos analisados, atribui-se um valor específico, conseqüentemente, cada pixel também obteve seu valor correspondente. A sobreposição dos pixels dos dois períodos resultou num novo conjunto de pixels. Conforme mencionado, estabeleceu-se 0 valor desses pixels mediante um processo aritmético. Por exemplo, a categoria capoeira apresentou um como valor de pixel. Se o valor obtido na combinação dos pixels nos dois períodos foi zero, não houve alteração, pois, nessa subtração, os pixels correspondentes possuíam o mesmo valor $(C=1$ e $C=1$ ). No entanto, se no mapeamento de 1986, uma área

\footnotetext{
${ }^{5}$ Processo no qual se insere um sistema de coordenadas em base digital por meio de pontos com coordenadas conhecidas.
} 
mapeada como capoeira passou para a categoria mapa em 2002 ( $C=1$ e $M=8$ ), o resultado foi diferente de zero, o que correspondeu à alteração do uso e ocupação do solo.

Aplicou-se a mesma metodologia para o mapa de evolução da cobertura vegetal, porém, com valores distintos dos utilizados para a obtenção do mapa de evolução do uso e ocupação do solo. 0 processo aritmético gerou novos pixels e seus intervalos de valores foram agrupados para a composição da legenda que descreveu as principais alterações na cobertura vegetal da área de estudo no período.

A combinação entre os dois mapeamentos de uso e ocupação do solo (1986 e 2002) permitiu a análise da evolução dessa temática na área de estudo. Tendo em vista a não uniformidade entre as categorias de uso e ocupação do solo nos dois períodos, efetuou-se uma padronização das classes com base no mapeamento de 2002. Incluiu-se a categoria campo sujo, por exemplo, presente no mapeamento de 1986, na categoria campo para a padronização junto ao mapeamento de 2002. Da mesma forma, as categorias horticultura, cultura e granjas foram caracterizadas como hortifrutigranjeiro. Esse procedimento facilitou a combinação e a análise da evolução do uso e ocupação do solo da região.

\section{Resultados}

\section{Evolução do uso e ocupação do solo na região da Serra do Boturuna}

A Figura 4, que descreve a evolução do uso e ocupação do solo no período, apresenta apenas duas categorias em sua legenda: as áreas com alteração e as sem alteração. 0 mapa demonstra os locais onde ocorreram as modificações, sem uma contribuição qualitativa detalhada sobre o tipo de alteração.

Com a análise quantitativa dos dados, é possível concluir que há um equilíbrio entre as áreas com alteração e as áreas sem alteração. Pouco mais de $45 \%$ da área de estudo passou por modificações e, em aproximadamente $55 \%$ da área, as tipologias de uso e ocupação do solo se mantiveram. A Figura 2 compara a porcentagem da área ocupada em cada categoria de uso e ocupação do solo nos dois períodos. Esses dados indicam que as principais alterações estão relacionadas à cobertura vegetal, porém, o detalhamento dessas informações foi descrito mais à frente. Com relação as modificações nas forma de uso e ocupação do solo, deve-se destacar 0 aumento das áreas urbanizadas e das áreas de chácaras, que passaram, respectivamente, de $0,92 \%$ e $1,77 \%$ em 1986 para $2,34 \%$ e $5,55 \%$ em 2002.

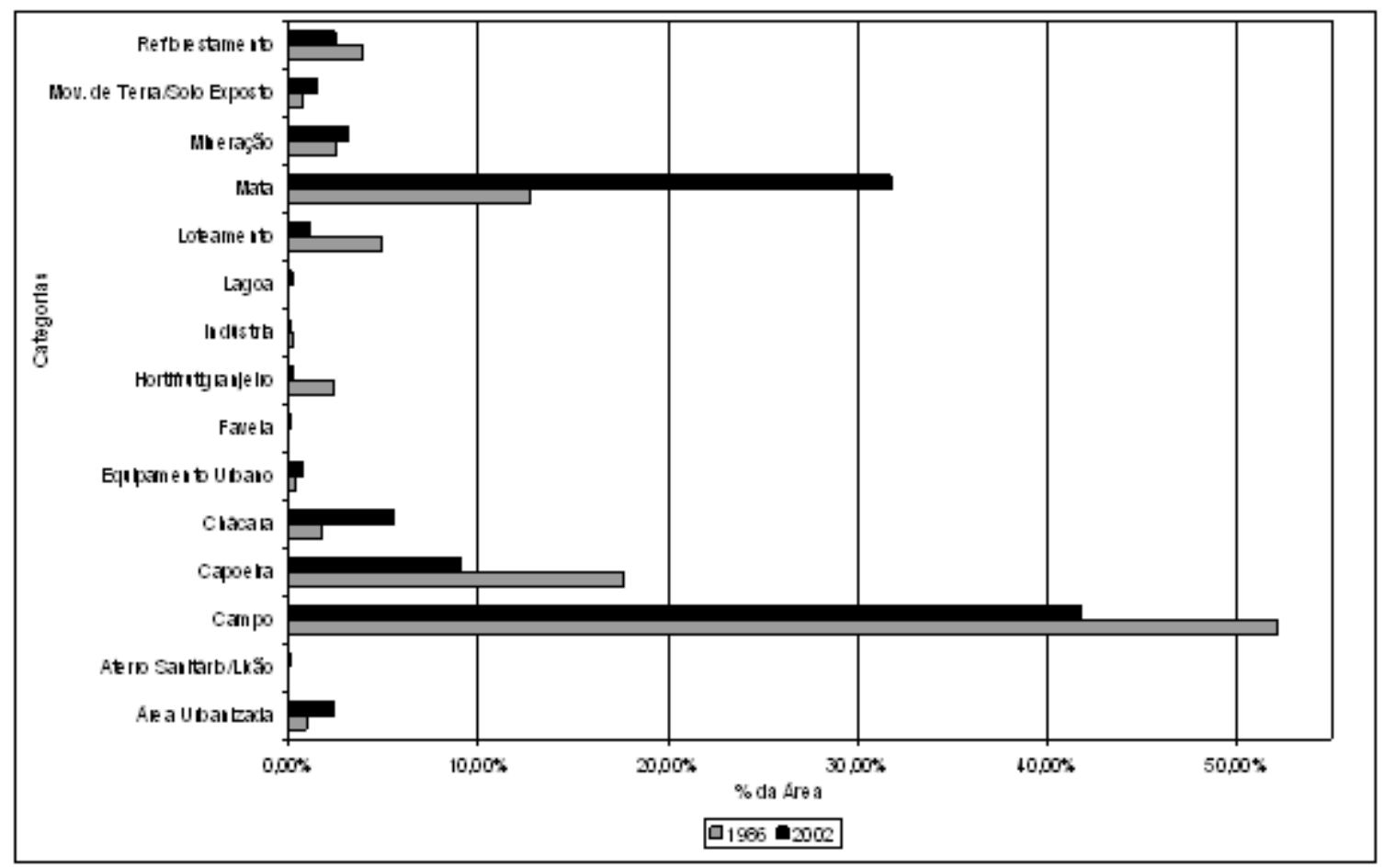

Figura 2 Distribuição espacial das categorias de uso e ocupação do solo na região da Serra do Boturuna, Estado de São Paulo (1986 a 2002) 
Verificou-se também que a área de estudo apresentou novas categorias de uso e ocupação do solo: uma favela e um aterro sanitário/lixão. Convém destacar que essas categorias não foram utilizadas no mapeamento de 1986.

A mineração, que consiste numa das principais atividades econômicas na região, apresentou reduzido aumento de área no período. A porcentagem de área ocupada por essa atividade é pouco superior a 3\%. No entanto, os impactos sobre a paisagem regional são significativos.

\section{Evolução da cobertura vegetal na região da Serra do Boturuna}

Segundo a Figura 2, as categorias de cobertura vegetal foram as que passaram por maiores modificações. Ao comparar os dois períodos, constatou-se que a cobertura florestal na área de estudo aumentou. $A$ área de mata, que em 1986 representava 12,68\% da área total, passou para 31,75\%. Nota-se, então, que esse aumento decorre da diminuição das áreas de capoeira e campo que passaram, respectivamente, de $17,63 \%$ e $52,18 \%$, em 1986 para $9,06 \%$ e $41,76 \%$, em 2002. Esses dados podem demonstrar a sucessão secundária da vegetação ocorrida na área de estudo.

Os dados demonstram que em torno de $50 \%$ da cobertura vegetal passou por modificações em relação ao mapeamento de 1986. Uma das principais alterações decorreu da conversão das capoeiras em áreas compostas por matas, que abrangeu, aproximadamente, $14 \%$ das alterações da cobertura vegetal na região. Por meio da análise da Figura 3 e da Figura 5, é possível verificar tais características. Contudo, devem-se destacar os setores a sudoeste da Serra do Boturuna, no município de Santana de Paranaíba. Possivelmente, nessa região, ocorreu a sucessão secundária da vegetação com uma evolução de capoeira para mata.

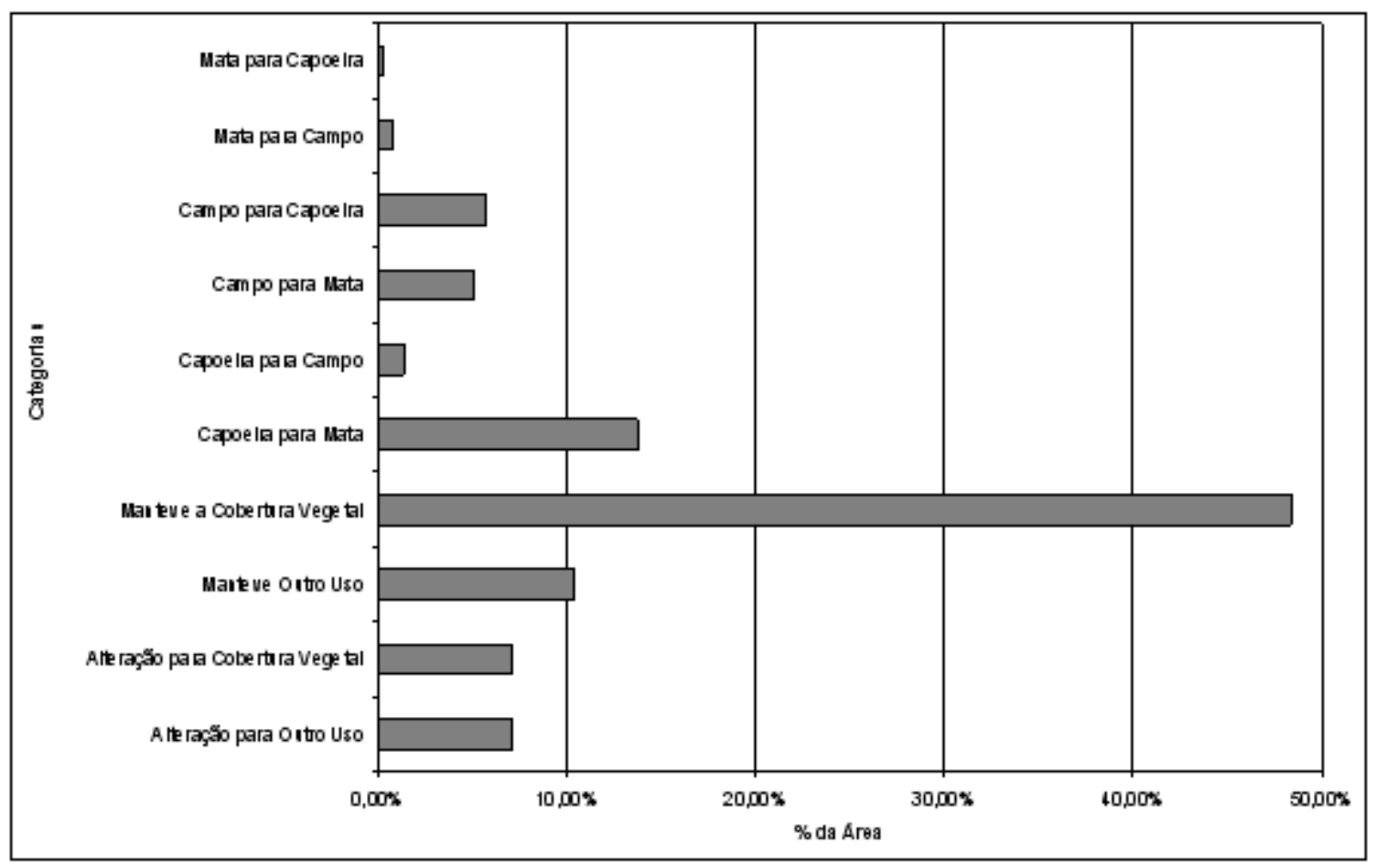

Figura 3 Evolução da distribuição espacial cobertura vegetal na região da Serra do Boturuna, Estado de São Paulo (1986 a 2002).

Verificou-se também a manutenção das áreas de reflorestamento, ou silvicultura. Convém destacar que o tombamento da Serra da Boturuna possui como um dos objetivos principais a garantia de sua preservação como patrimônio ambiental. No entanto, essa atividade econômica não contribui para esse propósito, em virtude do estabelecimento de uma monocultura de espécie exótica. Supõe-se que a atividade não deveria ocorrer no perímetro da área tombada $e$ seu entorno. Além da dispersão de espécies exóticas, a silvicultura não promove a diversidade biológica de espécies. A comparação entre os mapeamentos indica certa diminuição da distribuição espacial dessa cobertura, mas ainda há uma grande extensão de silvicultura no perímetro do tombamento. 


\section{Considerações Finais}

Os dados sobre a evolução do uso e ocupação do solo de determinada região, muitas vezes, são obtidos por meio do tratamento, da classificação automática e da subtração de imagens orbitais de dois períodos. Entretanto, neste estudo utilizaram as informações de mapeamentos realizados por técnicas de fotointerpretação e de interpretação em tela de imagens de satélite de alta resolução.

Os mapas e análise quantitativa dos dados demonstraram certo equilíbrio entre as áreas com alteração e as áreas sem alteração no uso e ocupação do solo na região da Serra do Boturuna. As principais alterações relacionam-se à cobertura vegetal. Verificou-se um aumento da cobertura florestal na área de estudo, o que, de certa forma, demonstra a sucessão secundária da vegetação. Sugere-se que a instituição da ANT da Serra do Boturuna, possivelmente, contribuiu para preservação e o aumento da cobertura florestal na região, sobretudo, em Santana de Parnaíba.

A metodologia e as técnicas empregadas permitiram a quantificação, o mapeamento e a análise das alterações no uso do solo e da cobertura vegetal entre os dois períodos. Esses procedimentos se adequaram aos objetivos da pesquisa e demonstraram um grau satisfatório de precisão. Deve-se ressaltar que nesse tipo de análise, torna-se necessária uma base cartográfica precisa, o que garantirá a precisão das informações processadas.

A Figura 4 forneceu a localização das áreas que passaram por alterações no período, porém, esse mapa não detalha o tipo de alteração. A Figura 5 traz informações qualitativas importantes que permitiram verificar o grau de preservação florestal na região. Esse mapa consistiu-se num importante instrumento para avaliar as modificações da cobertura vegetal na região e ponderar sobre a importância do estabelecimento da ANT da Serra do Boturuna.

\section{Agradecimentos}

Empresa Paulista de Planejamento Metropolitano S.A. (Emplasa).

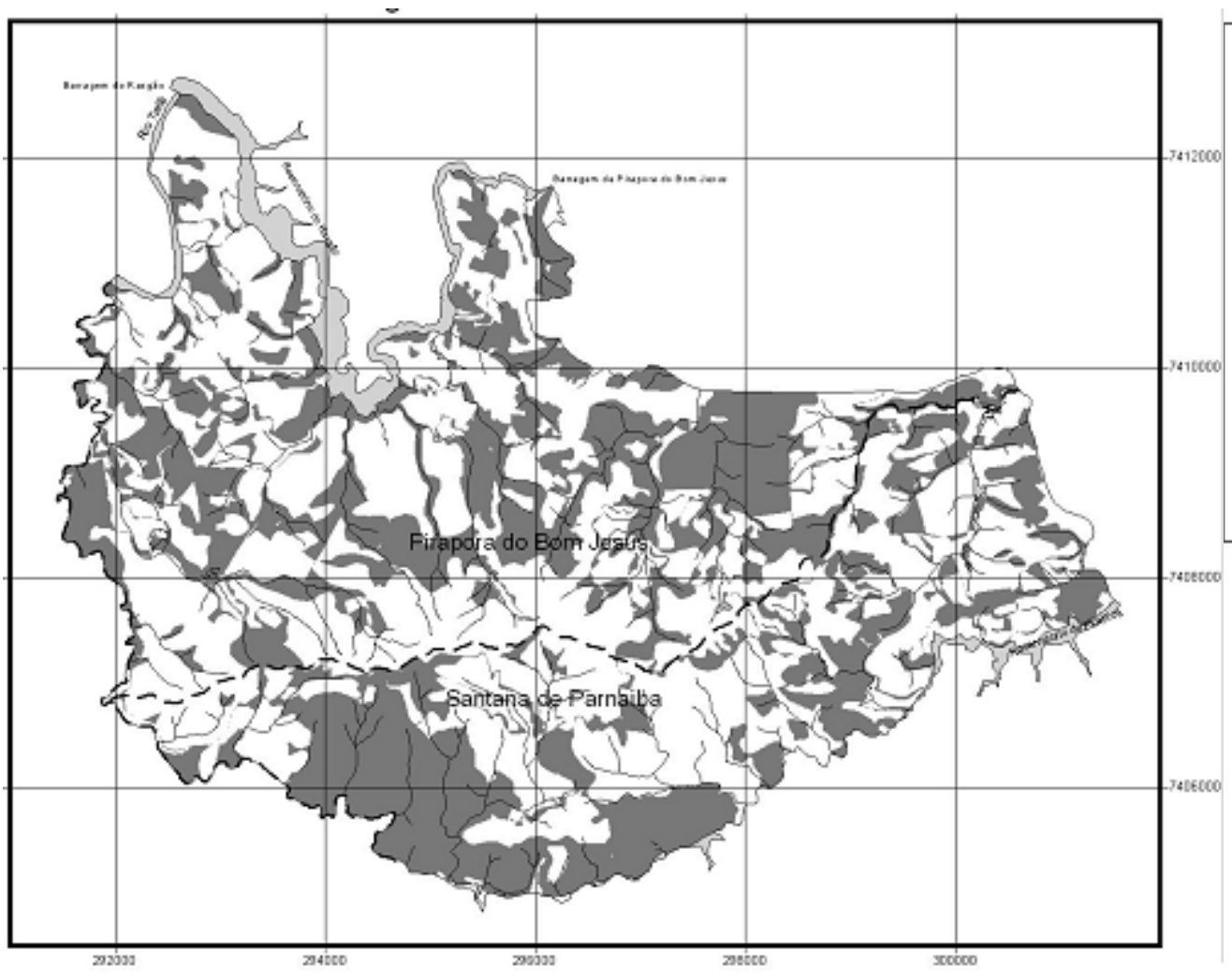

Convençōes Cartográficas

row corne ne Terreto

T Limst Nuricigal

Easato

$\square$ Lagaa A Represa

Carse 0\%oga Maira que $18 \mathrm{~m}$.

—Carso OHowamener que $10 \mathrm{~m}$.

Evoluçăo Uso e Ocupação do Solo

Com Altergega no Periodo

Sem Alteraçæo no Periodo
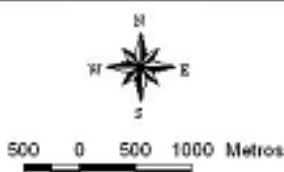

EST NOO DE SR̈O P AULO Locslizaçâo do Maps

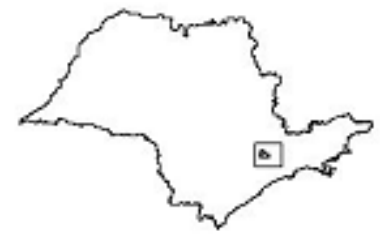

Figura 4 Mapa de evolução do uso e ocupação do solo no seríodo de 1986 a 2002: Região da Serra do Boturuna, Estado de São Paulo. 


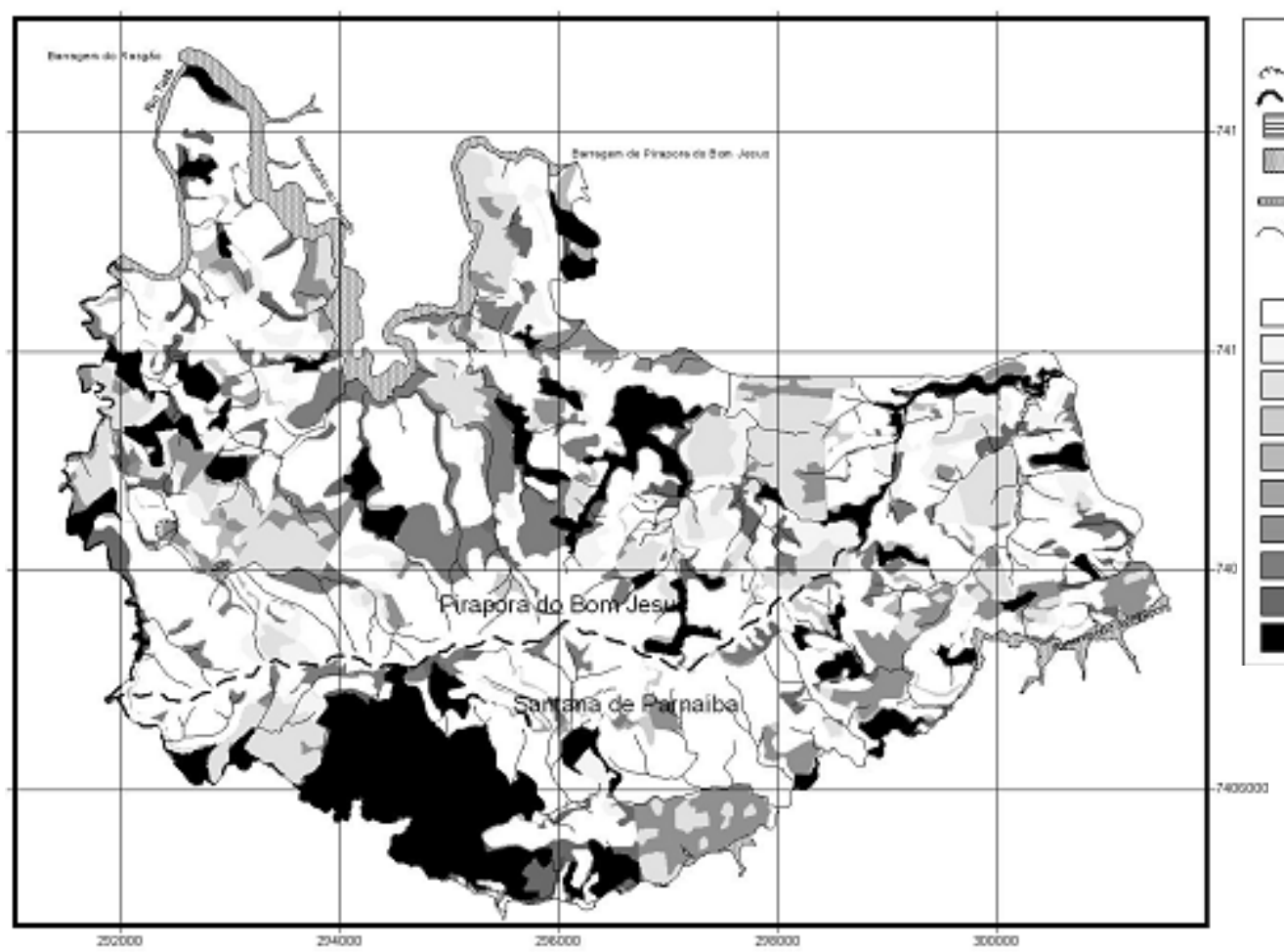

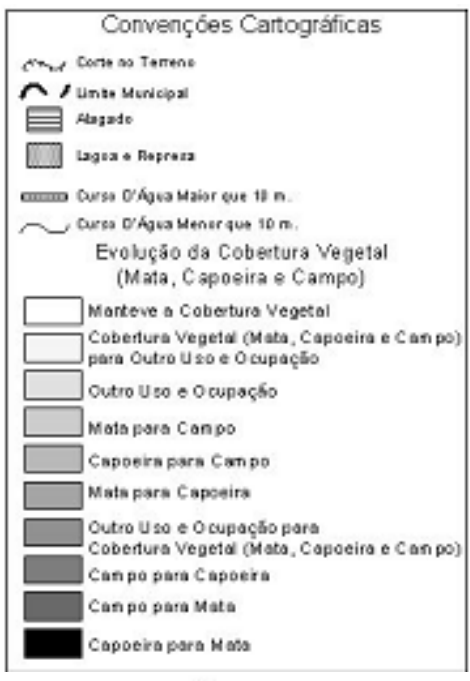

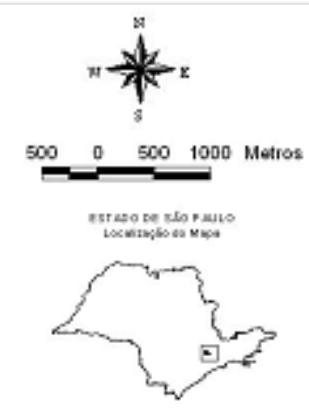

Figura 5 Evolução da cobertura vegetal no período de 1986 a 2002: Região da Serra do Boturuna, Estado de São Paulo. 
DETONI, S.F. (2010). Land use and vegetation cover evolution in the region of Serra do Boturuna, State of Sao Paulo. Revista do Departamento de Geografia, n. 20, p. 51 - 61.

Abstract: This work presents an analysis of the evolution of the land use and vegetation cover in the region of the Boturuna moutain range, in the state of São Paulo. Due to its peculiar landscape features, the Boturuna mountain range is considered by Conselho de Defesa do Patrimônio Histórico, Arqueológico, Artístico e Turístico do Estado de São Paulo (CONDEPHAAT) a natural heritage. The analysis was based on land occupation maps for the years between 1986 and 2002, made by Empresa Paulista de Planejamento Metropolitano (Emplasa). A Geographic Information System (GIS) allowed the generation of maps and data for the evolution of land use and vegetation cover at the region. The procedure indicated a primary forest cover increase and a decrease of secundary forest and grassland cover. The natural heritage creation has apparently contributed to the preservation of primary forest cover in the region.

Key words: Boturuna mountain range; Natural heritage; Land occupation and use; Geoprocessing.

Recebido em 12 de setembro de 2006, aceito em 01 de fevereiro de 2010.

\section{Referências}

AB'SÁBER, A. N. (1978) Parecer do Projeto de Urbanização da

Fazenda da Ilha, Municípios de Embu-Guaçu e São Paulo. São

Paulo: Emplasa, 1978. (Exigência EMPLASA 37/78). . (2003) Os Domínios de Natureza no Brasil: Potencialidades

Paisagísticas. São Paulo: Ateliê Editorial, 2003. 159 p.

EMPLASA. (1986) Empresa Paulista de Planejamento Metropolitano.

Cartas de Uso e Ocupação do Solo da Região Metropolitana de São Paulo. Sistema Cartográfico Metropolitanao Escala 1: 25.000. Follhas 144 e 243.

. (2005) Empresa Paulista de Planejamento Metropolitano. Cartas de Uso e Ocupação do Solo da Região Metropolitana de São Paulo e Bacia do Alto Tietê (2002). Sistema Cartográfico Metropolitano. Escala 1: 25.000 Folhas 144 e 243. São Paulo: EMPLASA, 2005.

IBGE. (2004) Instituto Brasileiro de Geografia e Estatística. Mapa de Vegetação do Brasil. IBGE: 2004.

SÃO PAULO (Estado). Secretaria daAgricultura (1975). Levantamento da Cobertura Vegetal Natural e do Reflorestamento no Estado de São Paulo. Coordenadoria da Pesquisa de Recursos Naturais. Instituto Florestal. Boletim Técnico n. 11: São Paulo, 1975. 2 ed.

UNESCO. (1973) United Nations Educational, Scientific and Cultural Organization. Internation Classification, and Mapping of Vegetation. E. Trilingüe. Série "Ecology and Conservation" n. 6: Paris, 1973. 
